УДК 661.183.2, 620.181.4

\title{
ВЛИЯНИЕ ПРЕДВАРИТЕЛЬНОЙ ВОДНОЙ ОБРАБОТКИ СОСНОВЫХ ОПИЛОК НА СТРУКТУРНЫЕ ИЗМЕНЕНИЯ ДРЕВЕСИНЫ И СВОЙСТВА УГЛЕРОДНОГО ПРОДУКТА НА ЕЕ ОСНОВЕ
}

\author{
() С.И. Цыганова , О.Ю. Фетисова, Г.Н. Бондаренко, Н.И. Павленко, Е.А. Андреева \\ Институт химии и химической технологии СО РАН, Академгородок, 50/24, \\ Красноярск, 660036 (Россия), e-mail: light@icct.ru
}

Изучено влияние длительной водной выдержки опилок сосны на структуру древесины и ее углеродного продукта. Установлено, что подобная обработка древесины приводит к увеличению доли аморфной фазы и содержания водорода в ее составе. С помощью рентгенофазового анализа определено, что после водной обработки древесины уменьшается степень кристалличности целлюлозы и повышается ширина размера кристаллитов. Выявлено, что повышенное содержание аморфной составляющей в древесине после водной обработки сохраняется в структуре углеродного продукта на ее основе по сравнению с необработанной древесиной и ее продукта.

Показана возможность получения пористых углеродных материалов из опилок древесины сосны, подвергнутых длительной выдержке в воде. Карбонизация этих опилок до $800^{\circ} \mathrm{C}$ приводит к образованию пористого углеродного продукта, удельная поверхность которого в 400 раз выше удельной поверхности продукта, полученного из обычных опилок в тех же условиях. Предполагается, что раскрытие пористой структуры углеродного продукта из древесины после водной обработки вызвано ее изменением, в том числе расширением кристаллической решетки целлюлозы, и удалением в процессе карбонизации образующихся низкомолекулярных фрагментов.

Ключевые слова: древесина сосны, водная обработка, карбонизация, пористый углеродный материал.

\section{Введение}

Переработка древесины и древесных отходов, накопление и разложение которых идет непрерывно, в полезные материалы является одной из постоянных задач человечества. Природное разложение древесины под действием воды, света, температуры, микроорганизмов и др. приводит к образованию огромного количества отходов, при этом на создание средств защиты древесины от разрушения выделяются огромные материальные средства $[1,2]$. В то же время эти отходы могут служить сырьем для получения новых материалов, включая углеродные сорбенты.

Цыганова Светлана Ивановна - старший научный сотрудник лаборатории процессов синтеза и превращения углеводородов, кандидат химических наук, e-mail: light@icct.ru

Фетисова Ольга Юрьевна - старший научный сотрудник лаборатории процессов синтеза и превращения углеводородов, кандидат химических наук, e-mail: fou1978@mail.ru

Бондаренко Галина Николаевна - старший научный сотрудник лаборатории рентгеновских и спектральных методов анализа, кандидат химических наук, e-mail: gal@ksc.krasn.ru

Павленко Нина Ивановна - ведущий научный сотрудник лаборатории молекулярной спектроскопии и анализа, кандидат химических наук, e-mail: pni@icct.ru Андреева Елена Алексеевна - ведущий технолог лаборатории рентгеновских и спектральных методов анализа, e-mail: andreeva121171@mail.ru
Несмотря на большое число теоретических и практических работ по синтезу углеродных сорбентов из древесины [3-5], исследований по влиянию природных факторов разложения древесины на пористую структуру углеродных сорбентов немного. Известны работы по изучению процессов разложения древесины под действием природных факторов: воздуха (кислорода), воды, солнечного света (теплового, ультрафиолетового излучения), микроорганизмов и др. [1, 2, 6, 7]. В работе [2] указывается, что бактериальное разложение древесины приводит к снижению содержания гемицеллюлоз и увеличению относительного количества лигнина, под действием света разложению в основном под-

\footnotetext{
* Автор, с которым следует вести переписку.
} 
вергается лигнин. Авторы работы [6] выявили, что содержание лигнина понижается в процессе старения дерева. Изучение образцов древесины сосны до и после выветривания различной степени разрушения с помощью методов рентгеновской дифракции и ИК-Фурье спектроскопии показало, что после выветривания степень кристалличности и размер кристаллитов целлюлозы повышается и понижается доля аморфной фракции в древесине [7]. Полоса поглощения при $1650 \mathrm{~cm}^{-1}$ в ИК спектрах различных пород древесины после выветривания ассоциируется с наиболее реакционноспособной поверхностной группой.

Что касается изучения влияния воды на структуру древесины, включая разрушение и поддержание процессов гниения и разложения, этот характер до конца не ясен $[8,9]$. Более того, работ по исследованию синтеза углеродных сорбентов из древесины, подвергнутой длительному воздействию воды, и по исследованию их структуры и свойств практически нет.

Цель данной работы - изучение влияния предварительной обработки (длительного вымачивания) опилок сосны в воде на структурные изменения древесины и свойства углеродного продукта на ее основе.

\section{Экспериментальная часть}

Опилки древесины сосны (ДС) деревоперерабатывающего предприятия ООО «Пышма» были взяты в качестве исходного сырья. Опилки сосны фракции 1-2 мм были выдержаны в воде при периодическом помешивании в течение одного года в закрытой емкости. Массовое соотношение ДХ $-\mathrm{H}_{2} \mathrm{O}$ составляло $1: 7$. Далее смесь древесины с водой (ДСВ) отфильтровывали и сушили до постоянной массы при $105^{\circ} \mathrm{C}$.

Для получения углеродного продукта опилки до и после водного вымачивания карбонизовали в проточной установке в токе аргона при скорости нагрева $10{ }^{\circ} \mathrm{C} \cdot$ мин $^{-1}$ при температурах 400 и $800{ }^{\circ} \mathrm{C}$. Элементный состав исходного сырья определяли на приборе FLASH EA 1112 (Italy). Термический анализ образцов проводили на термоанализаторе STA 449 F1 Jupiter в среде аргона и скорости нагрева $10^{\circ} \mathrm{C}_{\text {мин }}{ }^{-1}$. Удельную поверхность карбонизованных продуктов определяли по низкотемпературной адсорбции азота (77 К) с последующим расчетом полученных изотерм методом БЭТ.

Структуру и свойства древесины до и после вымачивания, а также продуктов их карбонизации исследовали, используя электронный микроскоп Hitachi ТМ-1000, рентгеновский дифрактометр ДРОН-3 и ИК-Фурье-спектрометр Tensor 27.

\section{Обсуждение результатов}

Представленная на рисунке 1 морфология древесины сосны показывает ее анизотропное строение в виде вытянутых длинных волокон с кососрезанными концами. После вымачивания ее в воде и последующей сушки наблюдается существенное разрушение волокон, уменьшение их длины и раскрытие внутренней поверхности (рис. 1б).

Рентгенофазовый анализ этих образцов подтверждает (рис. 2), что после выдержки древесины в воде происходит ее «мягкая модификация». На дифрактограмме видны два основных пика при $2 \theta=15-16^{\circ}$ и $22,6^{\circ}$, характеризующие аморфно-кристаллическое строение целлюлозы, соответствующих $\alpha$ - и $\beta$-целлюлозам [10-13]. При этом плотность рассеивающих атомов в плоскости (101) заметно повышается после обработки древесины водой, а интенсивность основного рефлекса отражения (002) уменьшается.

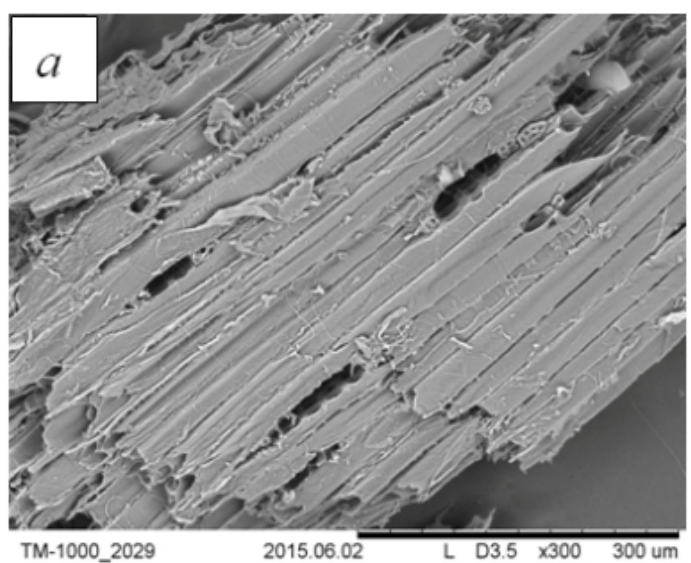

Рис. 1. Микрофотографии опилок древесины сосны до (а) и после (б) водной обработки

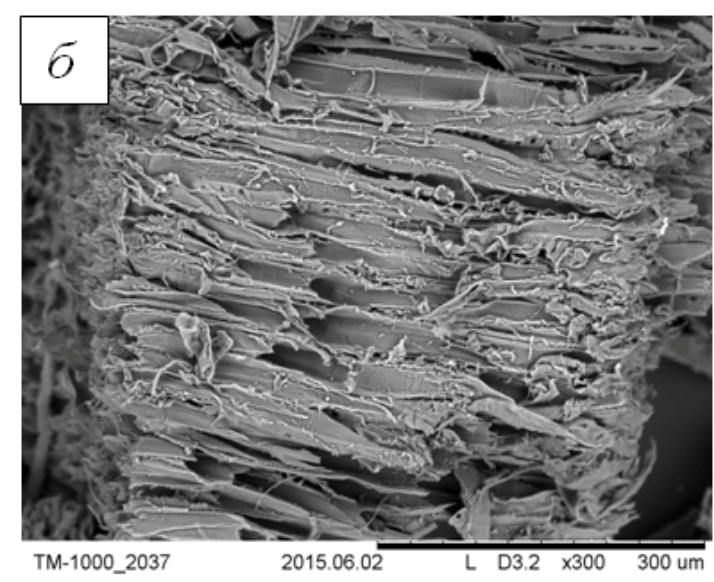


Рис. 2. Рентгенодифрактограмма опилок древесины сосны до (1) и после (2) вымачивания в воде. I - интенсивность сигнала (имп·с $\left.{ }^{-1}\right), 2 \theta-$ угол Брэгга (град)

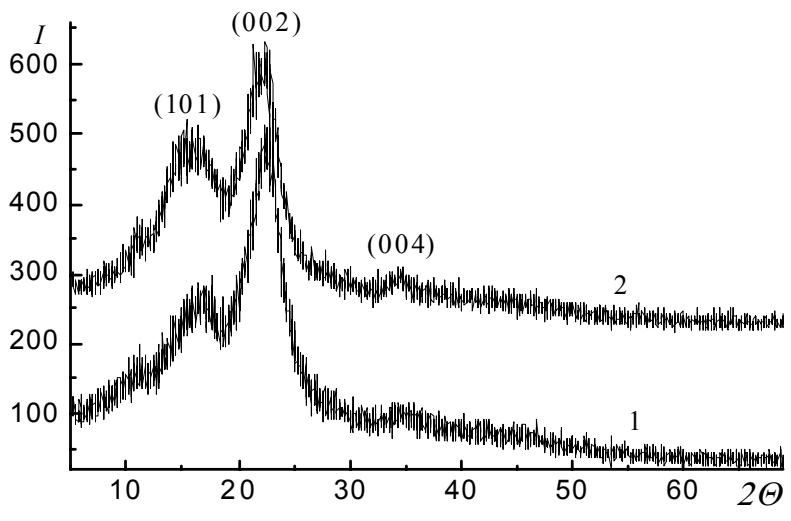

Определенный по методу Сегала $[1,8,12]$ индекс кристалличности целлюлозы $(\mathrm{CI})$ :

$$
\mathrm{CI}=\left(\mathrm{I}_{002}-\mathrm{I}_{\text {аморф }}\right) * 100 / \mathrm{I}_{002},
$$

где $\mathrm{I}_{002}$ - высота рефлекса (002) при $2 \theta=22,5^{\circ}, \mathrm{I}_{\text {аморф }}$ - высота полосы при $2 \theta=18^{\circ}$, составляет 55 и $48 \%$ соответственно для древесины до и после водной обработки. Понижение кристалличности происходит, по-видимому, благодаря проникновению молекул воды в структуру целлюлозы, которые связываются Нсвязями с доступными, полярными ОН-группами, тем самым приводя к увеличению доли аморфной составляющей. Об этом свидетельствует и ширина кристаллитов, рассчитанная по уравнению Шеррера [1]:

$$
\mathrm{D}_{002}=\mathrm{k} \cdot \lambda / \mathrm{B}_{002} \cdot \cos \theta \text {, }
$$

где $\mathrm{k}$ - константа Шеррера $(0,84), \lambda$ - длина волны рентгеновского излучения $(0,154$ нм), В - ширина на $1 / 2$ высоте рефлекса (002) в радианах, $\theta$ - угол Брэгга. Ширина кристаллитов целлюлозы, содержащейся в исходной ДС, составляет 1,5 нм, а после водной выдержки древесины она равна 1,9 нм, подтверждая возможность включения молекул воды в решетку целлюлозы. Схему воздействия воды на фрагмент древесины можно изобразить на примере адсорбции воды в целлюлозном волокне [14] (рис. 3).

В таблице 1 приведены данные элементного анализа исходных образцов до и после водной обработки. Как видно, состав основных элементов в этих образцах близкий.

Однако можно отметить, что доля углерода и водорода несколько выше, а доля кислорода ниже в образце, предварительно обработанном в воде. При этом отношение $\mathrm{C} / \mathrm{H}$ после водной обработки уменьшается, а отношение С/O растет. Это еще раз подтверждает, что разложение древесины под действием воды прежде всего вызвано взаимодействием полярных ОН-групп компонентов биомассы, включая целлюлозу, с водой и образованием слабосвязанных структур и низкомолекулярных кислородсодержащих соединений, которые удаляются в процессе дальнейшей фильтрации и сушки образца, что приводит к росту доли водорода в составе образца.

На рисунке 4 приведены ИК спектры исходных образцов до (кривая 1) и после обработки в воде (кривая 2). Идентичность спектральных картин представленных спектров свидетельствует о том, что структурно-групповой состав образцов практически одинаков. Однако в спектре образца, выдержанного в воде (рис. 3, кривая 2), заметно понижается интенсивность как полосы поглощения с максимумом 3428 см$^{-1}$, характеризующей адсорбированную воду и вовлечение ОН-групп в меж-, внутримолекулярную водородную связь, так и интенсивность полос поглощения в области (fingerprint region) 1750-500 см ${ }^{-1}$ [15]. Это еще раз доказывает вовлечение ОН-групп компонентов биомассы в процесс ее деструкции.

Рис. 3. Адсорбция воды аморфной составляющей микрофибриллы целлюлозы [14]

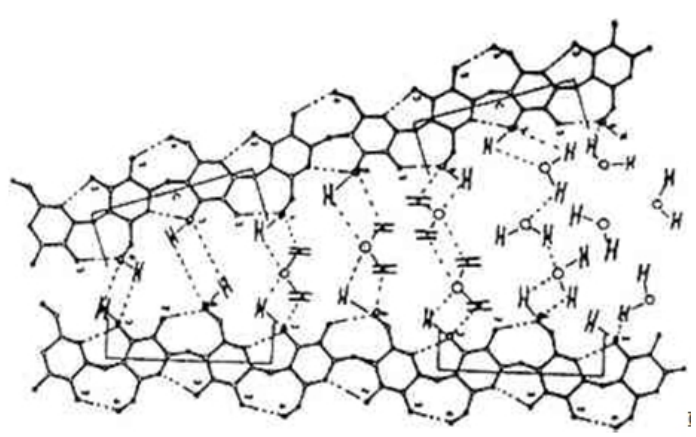


Таблица 1. Элементный состав опилок древесины сосны до (ДС) и после (ДСВ) водной обработки

\begin{tabular}{c|c|c|c|c|c}
\hline \multirow{2}{*}{ Образец } & \multicolumn{3}{|c|}{ Элементный состав, \% } & \multicolumn{2}{c}{ Молярное отношение } \\
\cline { 2 - 6 } & $\mathrm{C}$ & $\mathrm{H}$ & $\mathrm{O}$ & $\mathrm{C} / \mathrm{H}$ & $\mathrm{C} / \mathrm{O}$ \\
\hline ДС & 49,48 & 5,65 & 42,48 & 0,73 & 1,55 \\
ДСВ & 49,95 & 6,09 & 41,07 & 0,68 & 1,62 \\
\hline
\end{tabular}

Примечание. Точность определения прибора $1 \cdot 10^{-6} \%$

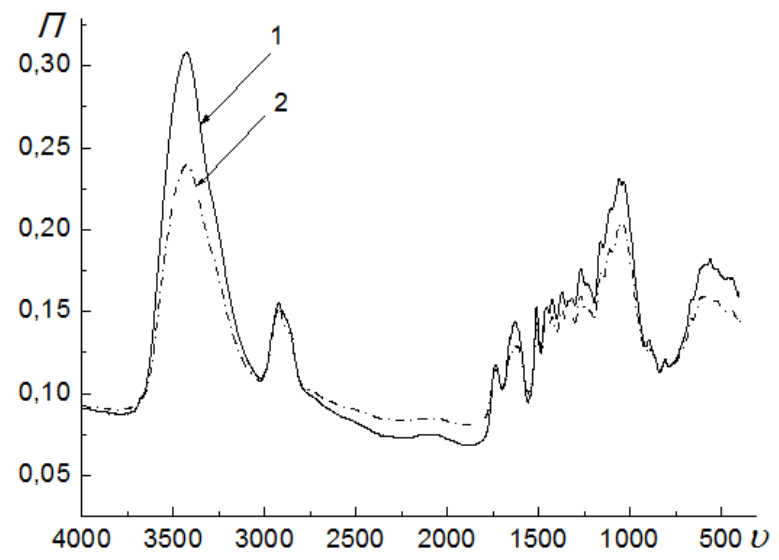

Рис. 4. ИК-спектры опилок древесины сосны до (1) и после (2) выдержки в воде. П- поглощение, отн. ед., $v$ - волновое число, $\mathrm{cm}^{-1}$

Таким образом, длительное воздействие воды на древесину сосны можно описать следующим образом: молекулы воды, проникая в макроструктуру древесины, приводят к набуханию, расширению кристаллической решетки целлюлозы и частичному ее растворению за счет образования водно-водородных связей молекул воды с гидроксильными группами целлюлозы; при последующей сушке удаляется вся влага, втянутая гидроксильными группами целлюлозы в процессе набухания, разрушаются водородные связи между гидроксилами смежных цепей целлюлозы и высвобождается большое количество гидроксильных групп.

Результаты по выходу и удельной поверхности углеродных продуктов, полученных при карбонизации этих образцов, приведены в таблице 2.

Как видно, выход углеродного продукта из ДСВ несколько меньше, чем из ДС, однако удельная поверхность, имеющая близкие значения для обоих образцов, полученных при $400{ }^{\circ} \mathrm{C}$, существенно растет при нагреве ДСВ до $800^{\circ} \mathrm{C}$. Увеличение удельной поверхности на два порядка может быть связано с образованием низкомолекулярных фрагментов в древесине под действием воды и последующим их удалением в виде летучих продуктов в процессе высокотемпературной конденсации и упорядочения структуры углеродного продукта.

Процесс термолиза образцов ДС и ДСВ приведен на рисунке 5. Скорость убыли массы исходной и обработанной водой древесины сходна (рис. 5а). Основная потеря массы для этих образцов происходит в области $235-400{ }^{\circ} \mathrm{C}$.

Наблюдаемый эндотермический эффект в интервале температур $30-145^{\circ} \mathrm{C}$ связан с испарением адсорбированной воды (рис. 5б). Повышение температуры приводит к термораспаду образцов, причем этот интервал температур для ДСВ примерно на 15\% шире интервала температур ДС, что, косвенно указывает на более глубокие процессы термопревращения в ДСВ.

Приведенные дифрактограммы углеродных продуктов, полученных при карбонизации до $800{ }^{\circ} \mathrm{C}$ (рис. 6), выявляют слабые дифракционные полосы при $25^{\circ}$ и $43^{\circ}$, характеризующие аморфоподобную структуру углеродных продуктов. Более низкая интенсивность рефлекса (002) в спектре продукта из ДСВ (рис. 6, линия 2), чем в спектре продукта из ДС (рис. 6, линия 1), косвенно свидетельствует о большем содержании аморфной фазы в первом и, следовательно, более изотропной, пористой структуры углеродного материала из древесины, подвергнутой водному воздействию, чем из обычной древесины. Таким образом, водная обработка древесины приводит к повышению аморфной составляющей не только в древесине, но и в структуре ее углеродного продукта.

Таблица 2. Выход и удельная поверхность углеродного продукта, полученного при карбонизации древесины сосны до (ДС) и после (ДСВ) водной обработки

\begin{tabular}{c|c|c|c|c}
\hline \multirow{2}{*}{ Образец } & \multicolumn{3}{|c|}{ Выход, мас.\% } & \multicolumn{2}{c}{ Удельная поверхность, $\mathrm{M}^{2} / \Gamma$} \\
\cline { 2 - 5 } & 400 & 800 & 400 & 800 \\
\cline { 2 - 5 } & 31,6 & 22,9 & 20,8 & 1,1 \\
ДС & 24,6 & 19,2 & 18,4 & 408,8 \\
\hline
\end{tabular}



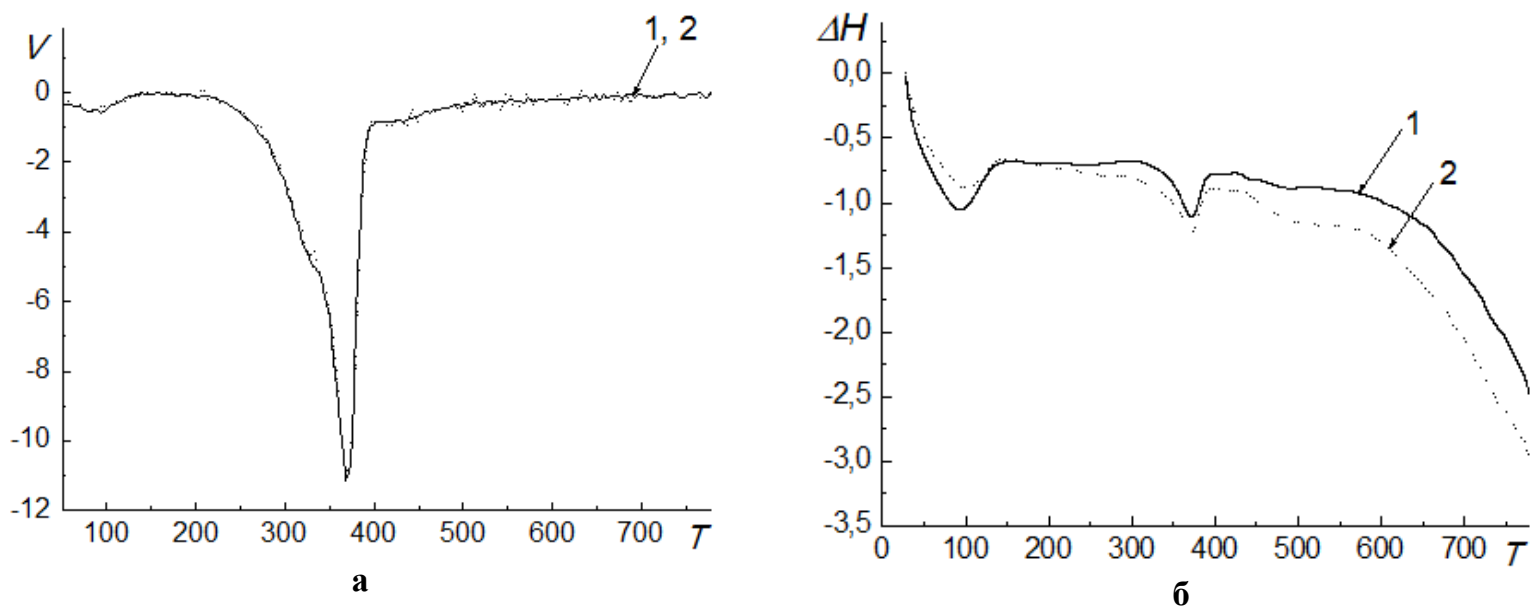

Рис. 5. Дифференциально-термический анализ образцов ДС (1) и ДСВ (2). $V$ - скорость убыли массы, \%·мин-1, $\Delta H$ - тепловой эффект, мВт·м $\Gamma^{-1}, T-$ температура, ${ }^{\circ} \mathrm{C}$

Рис. 6. Рентгенодифрактограмма углеродного продукта, полученного при $800{ }^{\circ} \mathrm{C}$ из опилок древесины сосны до (1) и после (2) вымачивания в воде. I - интенсивность сигнала (имп· $c^{-1}$ ), $2 \Theta-$ угол Брэгга (град).

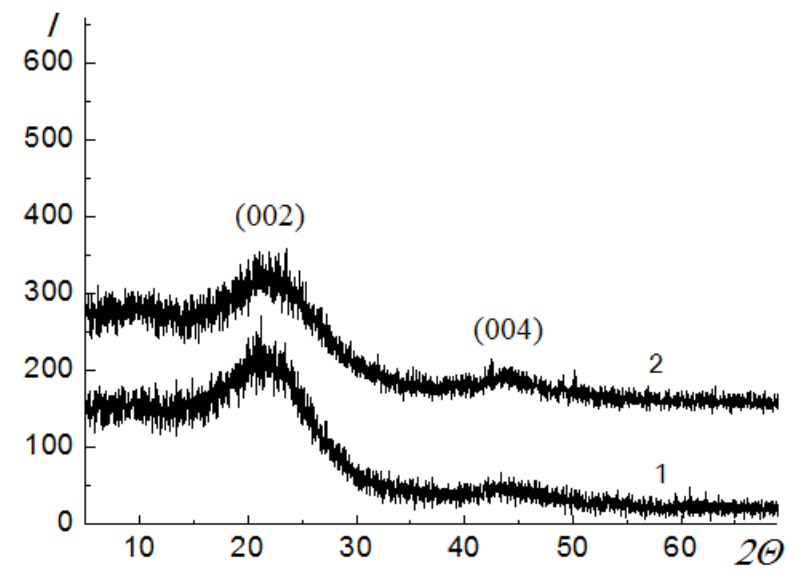

\section{Выводы}

1. Изучено влияние длительной водной обработки на структуру древесины сосны. Установлено, что в результате вымачивания происходит «мягкое разложение» древесины с увеличением доли аморфной составляющей и уменьшением содержания $\alpha$-целлюлозы в ней. Показано, что в процессе разложения биомассы под действием воды основную роль играют полярные ОН-группы компонентов биомассы, включая целлюлозы.

2. Выявлено, что повышенное содержание аморфной составляющей в предварительно обработанной древесине наблюдается также и в углеродном продукте на ее основе по сравнению с необработанной древесиной и ее продуктом.

3. Получен пористый углеродный продукт из древесины сосны после водного вымачивания, удельная поверхность которого на два порядка выше, чем удельная поверхность продукта, полученного из обычных опилок в тех же условиях.

Авторы выражают благодарность за помощь в работе Красноярскому региональному центру коллективного пользования СО РАН.

\section{Список литературы}

1. Lionetto F., Del Sole R., Cannoletta D. et al. Monitoring wood degradation during Weathering by Cellulose Crystallinity // Materials. 2012. Vol. 5. Pp. 1910-1922.

2. Dobrică I., Bugheanu P., Stănculescu I.et al. FTIR spectral data of wood used in Romanian traditional village constructions // Analele Universitătii din Bucureşti - Chimie. 2008. Anul. XVII. Vol. 1. Pp. 33-37.

3. Marsh H., Rodriguez-Reinoso F. Activated Carbon. Elsevier Ltd., 2006. 536 p.

4. Tsyganova S.I., Korol'kova I.V., Chesnokov N.V., Kuznetsov B.N. Formation of the porous structure of carbon materials during carbonization of microcrystalline cellulose modified by phosphoric acid // Russian Journal of Bioorganic Chemistry. 2011. Vol. 37, N7. Pp. 809-813.

5. Tsyganova S., Patrushev V., Zhizhaev A. Gold deposition on magnetic porous composites synthesized from modified wood sawdust at different temperatures // Wood Sci. Technol. 2015. Pp. 869-878. 
6. Azadfallah M., Mirshokraei S.A., Latibari A.J., Parsapajouh D. Analysis of Photodegraded Lignin on Cellulose Matrix by Means of FTIR Spectroscopy and High Pressure Size Exclusion Chromatography // Iranian Polymer Journal. 2008. Vol. 17, N1. Pp. 73-80.

7. Anderson E.L., Pawlak Z., Owen N.L. et al. Infrared studies of wood weathering. Part I: Softwoods// Applied Spectroscopy. 1991. Vol. 45. Pp. 641-647.

8. Engelund E.T., Thygesen L.G., Svensso S. et al. A critical discussion of the physics of wood-water interactions // Wood Sci. Technol. 2013. Vol. 47. Pp. 141-164.

9. Березин А.С., Тужиков О.И. Механизмы растворения целлюлозы в прямых водных растворителях (обзор) // Известия Волгоградского государственного технического университета. 2010. Т. 2, №62. С. 5-23.

10. Алешина Л.А., Глазкова С.В., Луговская Л.А. и др. Современные представления о строении целлюлоз (обзор) // Химия растительного сырья. 2001. №1. С. 5-36.

11. Manoj B., Kunjomana A.G. Study of stacking structure of amorphous carbon by X-ray diffraction technique // Int. J. Electrochem. Sci. 2012. Vol. 7. Pp. 3127-3134.

12. Terinte N., Ibbett R., Schuster K.C. Overview on native cellulose and microcrystalline cellulose I structure studied by x-ray diffraction (WAXD): comparison between measurement techniques // Lenzinger Berichte. 2011. Vol. 89. Pp. 118-131.

13. Khazraji A.C., Robert S. Self-assembly and intermolecular forces when cellulose and water interact using molecular modeling // J. of Nanomaterials. 2013. Vol. 2013. Pp. 1-10.

14. Pandey K.K., Theagarajan K.S. Analysis of wood surfaces and ground wood by diffuse reflectance (DRIFT) and photoacoustic (PAS) Fourier transform infrared spectroscopic techniques // Holz als Roh - und Werkstoff. 1997. Vol. 55, N6. Pp. 383-390.

15. Юхневич Г.В. Инфракрасная спектроскопия воды. М., 1973. 211 с.

Поступило в редакииюю 2 июля 2015 г.

После переработки 2 ноября 2015 г. 
Tsyganova S.I. ${ }^{*}$, Fetisova O.Iu., Bondarenko G.N., Pavlenko N.I., Andreeva E.A. EFFECT OF WATER TREATMENT PROVISIONAL PINE SAWDUST WOOD FOR STRUCTURAL CHANGES AND PROPERTIES CARBON PRODUCTS BASED ON IT

Institute of Chemistry and Chemical Technology, Siberian Branch of the Russian Academy of Sciences,

Akademgorodok, 50/24, Krasnoyarsk, 660036 (Russia), e-mail: light@icct.ru

The effect of long-term water extract of pine sawdust on the structure of wood and its carbon product. It is found that such a timber processing increases the fraction of the amorphous phase and the content of hydrogen in its composition. Using $\mathrm{X}$-ray diffraction is determined that the processing of wood after water decreases the crystallinity of cellulose and increases the width of the crystallite size. It is revealed that an increased content of amorphous component in the timber after the water processing is stored in the structure of the carbon product based on it, compared with an untreated timber and its product.

The possibility of producing porous carbon materials from sawdust pine subjected to long exposure to water. Carbonation of these chips, up to $800{ }^{\circ} \mathrm{C}$ leads to the formation of a porous carbon product, specific surface of which is 400 times higher than the specific surface area of product obtained from conventional chips in the same conditions. It is assumed that the disclosure of the porous structure of the carbon product from the timber after the water treatment due to the change of its structure, including the expansion of the crystal lattice of cellulose, and removing formed during carbonization of low molecular weight fragments.

Keywords: pine wood, water treatment, carbonization, the porous carbon material.

\section{References}

1. Lionetto F., Del Sole R., Cannoletta D. et al. Materials, 2012, vol. 5, pp. 1910-1922.

2. Dobrică I., Bugheanu P., Stănculescu I.et al. Analele Universitătii din Bucureşti - Chimie, 2008, Anul. XVII, vol. 1, pp. 33-37.

3. Marsh H., Rodriguez-Reinoso F. Activated Carbon. Elsevier Ltd., 2006. 536 p.

4. Tsyganova S.I., Korol'kova I.V., Chesnokov N.V., Kuznetsov B.N. Russian Journal of Bioorganic Chemistry, 2011, vol. 37 , no. 7, pp. 809-813.

5. Tsyganova S., Patrushev V., Zhizhaev A. Wood Sci. Technol., 2015, pp. 869-878.

6. Azadfallah M., Mirshokraei S.A., Latibari A.J., Parsapajouh D. Iranian Polymer Journal, 2008, vol. 17, no. 1, pp. 73-80.

7. Anderson E.L., Pawlak Z., Owen N.L. et al. Applied Spectroscopy, 1991, vol. 45, pp. 641-647.

8. Engelund E.T., Thygesen L.G., Svensso S. et al. Wood Sci. Technol., 2013, vol. 47, pp. 141-164.

9. Berezin A.S., Tuzhikov O.I. Izvestiia Volgogradskogo gosudarstvennogo tekhnicheskogo universiteta, 2010, vol. 2, no. 62, pp. 5-23. (in Russ.).

10. Aleshina L.A., Glazkova S.V., Lugovskaia L.A., Podoinikova M.V., Fofanov A.D., Silina E.V. Khimiia rasti-tel'nogo syr'ia, 2001, no. 1, pp. 5-36. (in Russ.).

11. Manoj B., Kunjomana A.G. Int. J. Electrochem. Sci., 2012, vol. 7, pp. 3127-3134.

12. Terinte N., Ibbett R., Schuster K.C. Lenzinger Berichte, 2011, vol. 89, pp. 118-131.

13. Khazraji A.C., Robert S. J. of Nanomaterials, 2013, vol. 2013, pp. 1-10.

14. Pandey K.K., Theagarajan K.S. Holz als Roh-und Werkstoff, 1997, vol. 55, no. 6, pp. 383-390.

15. Iukhnevich G.V. Infrakrasnaia spektroskopiia vody. [Infrared spectroscopy of water]. Moscow, 1973, 211 p. (in Russ.).

Received July 2, 2015

Revised November 2, 2015

\footnotetext{
* Corresponding author.
} 
